\title{
Heterogeneous Nickel catalysts derived from 2D metal-organic frameworks for regulating the selectivity of furfural hydrogenation
}

\author{
Pengfei Guo, ${ }^{a}$ Shengyun Liao,,${ }^{\mathrm{a},}$ Xinli Tonga,
}

a Tianjin Key Laboratory of Organic Solar Cells and Photochemical Conversion, School of Chemistry and Chemical Engineering, Tianjin University of Technology, No. 391 Binshuixi Road, Tianjin 300384, PR China

${ }^{*}$ E-mail for S. L.:18202587221@163.com. Tel./Fax: (+86)-22-6021-4259

*E-mail for X. T.: tongxinli@tju.edu.cn. Tel./Fax: +86)-22-6021-4259.

\section{Table of contents}

GC analysis for products of furfural hydrogenation in methanol with Ni-MFC-500 as catalyst $\quad$ S2

GC-MS analysis for products of furfural hydrogenation in methanol with Ni-MFC-500 as catalyst $\quad$ S3

GC analysis for products of furfural hydrogenation in methanol with Ni-MFC-700 as catalyst $\quad$ S4

GC-MS analysis for products of furfural hydrogenation in methanol with Ni-MFC-700 as catalyst $\quad$ S5

The Ni content in the Ni-MFC-500 and Ni-MFC-700 catalysts $\quad$ S6

$\begin{array}{ll}\text { Element mapping and EDS from HRTEM images of Ni-MFC-500 } & \text { S7 }\end{array}$

Element mapping from HRSEM images of Ni-MFC-500 $\quad$ S8

XPS analysis for the Ni-MFC-500 S9

XPS analysis for the Ni-MFC-700 S9

$\begin{array}{lr}\text { Nitrogen adsorption-desorption isotherm of the catalysts } & \text { S9 }\end{array}$

$\begin{array}{lr}\text { Textural parameters for the derived Ni-MFC catalysts } & \text { S10 }\end{array}$

$\begin{array}{ll}\mathrm{CO}_{2} \text {-TPD profiles of the catalysts } & \mathrm{S} 10\end{array}$

$\begin{array}{ll}\mathrm{H}_{2} \text {-pulse chemisorption profiles of the catalysts } & \mathrm{S} 10\end{array}$

$\mathrm{H}_{2}$-pulse chemisorption parameters for the derived Ni-MFC catalysts $\quad$ S11

$\mathrm{H}_{2}$-TPR profiles of the catalysts $\quad$ S11

$\mathbf{N H}_{3}$-TPD profiles of the catalysts $\quad$ S11 


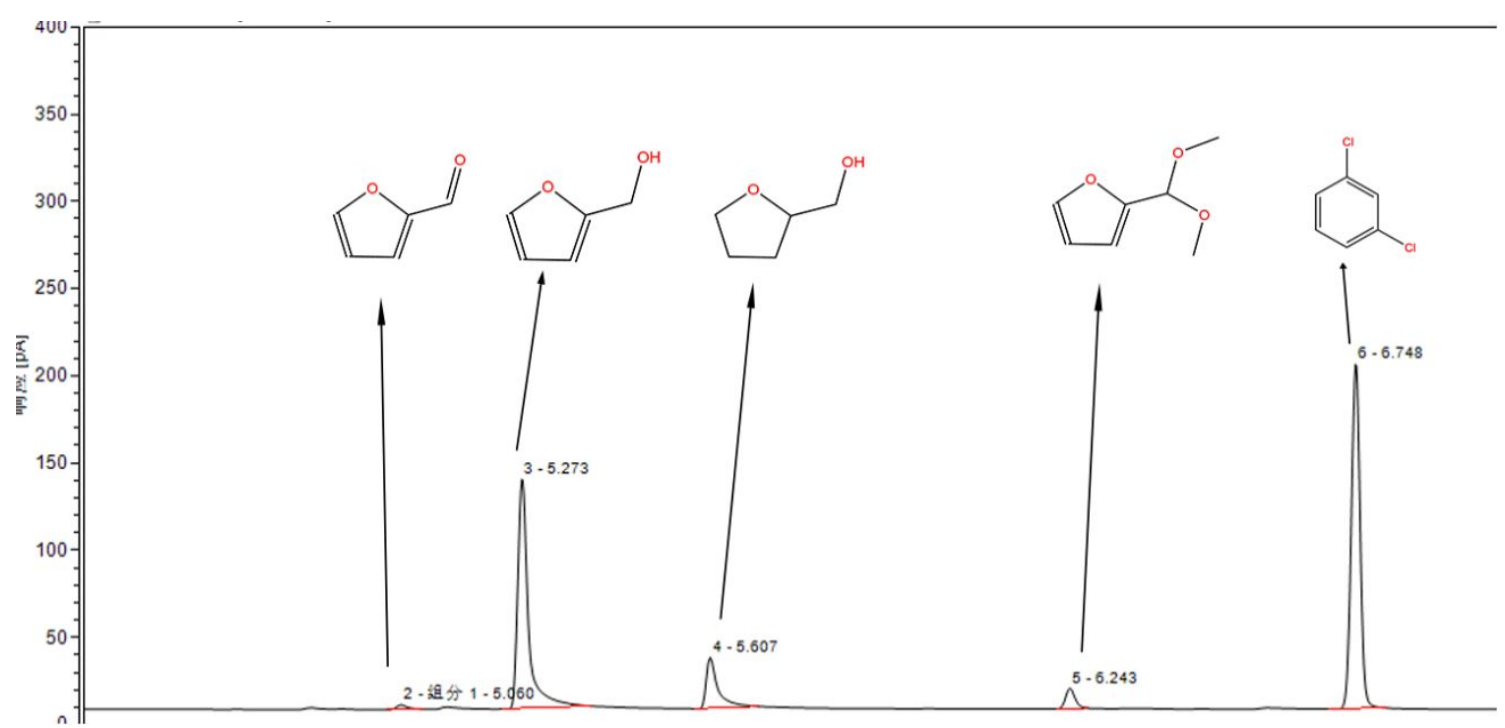

Figure S1. GC analysis for products of furfural hydrogenation with Ni-MFC-500 ( Reaction condition: $0.1 \mathrm{~g}$ furfural, methanol $(15 \mathrm{~mL}), 2 \mathrm{MPa}$ of $\mathrm{H}_{2}$, at $160^{\circ} \mathrm{C}$ for $\left.4 \mathrm{~h}\right)$. 

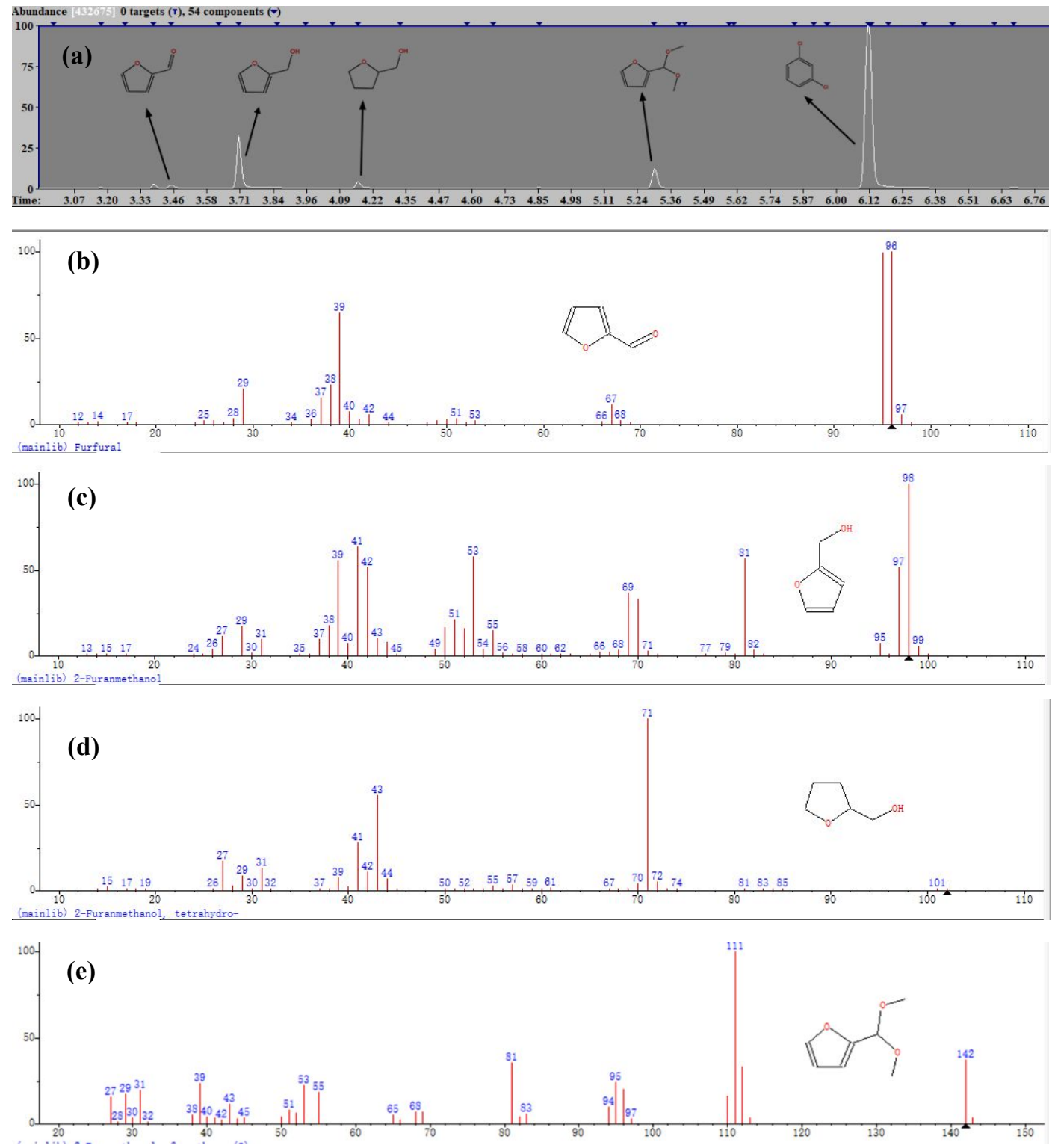

Figure S2. GC-MS analysis for products of furfual hydrogenation in methanol with Ni-MFC500 catalyst: (a.) GC spectrum of the reaction mixtures; (b) MS analysis for furfural; (c) MS analysis for FOl; (d) MS analysis for THFOL; (e) MS analysis for acetal. 


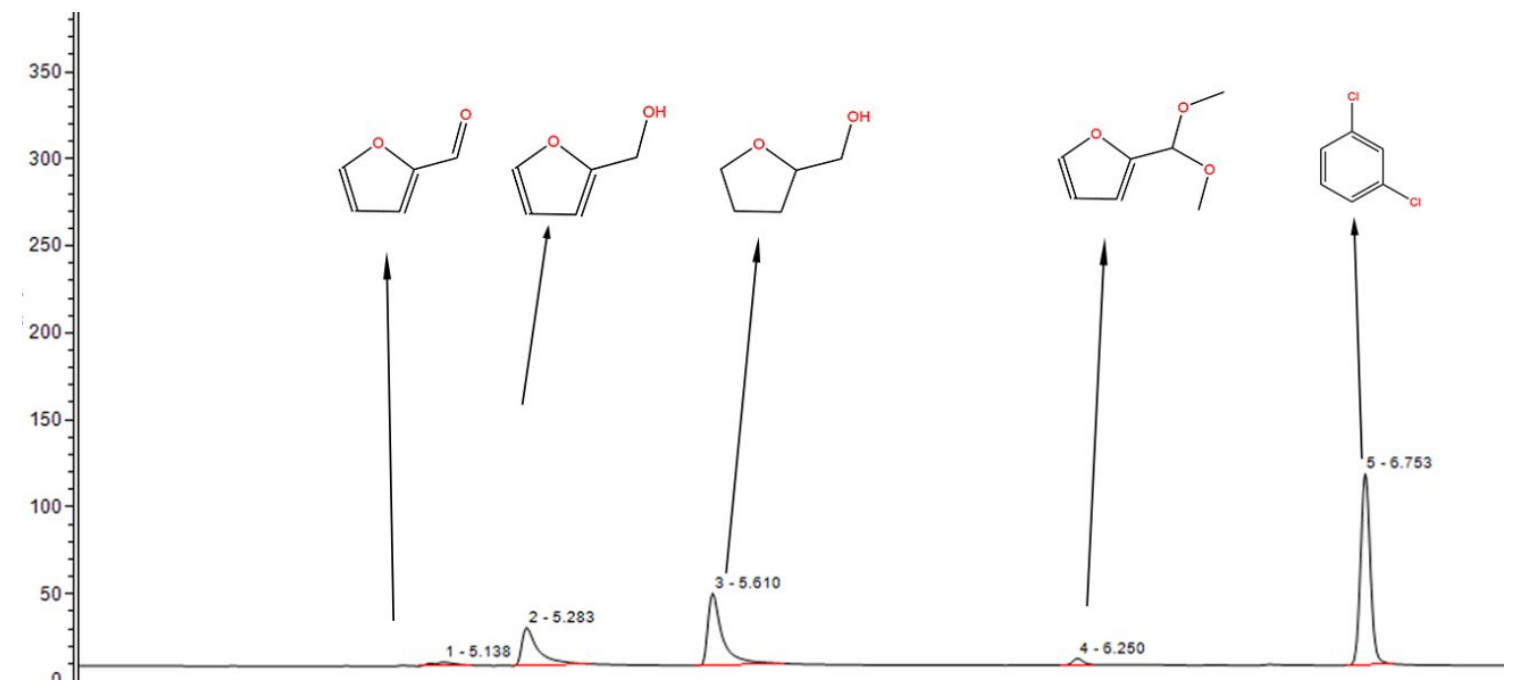

Figure S3. GC analysis for products of furfural hydrogenation with Ni-MFC-700: Reaction condition: $0.1 \mathrm{~g}$ furfural, methanol $(15 \mathrm{~mL}), 2 \mathrm{MPa}$ of $\mathrm{H}_{2}$, at $160{ }^{\circ} \mathrm{C}$ for $4 \mathrm{~h}$. 

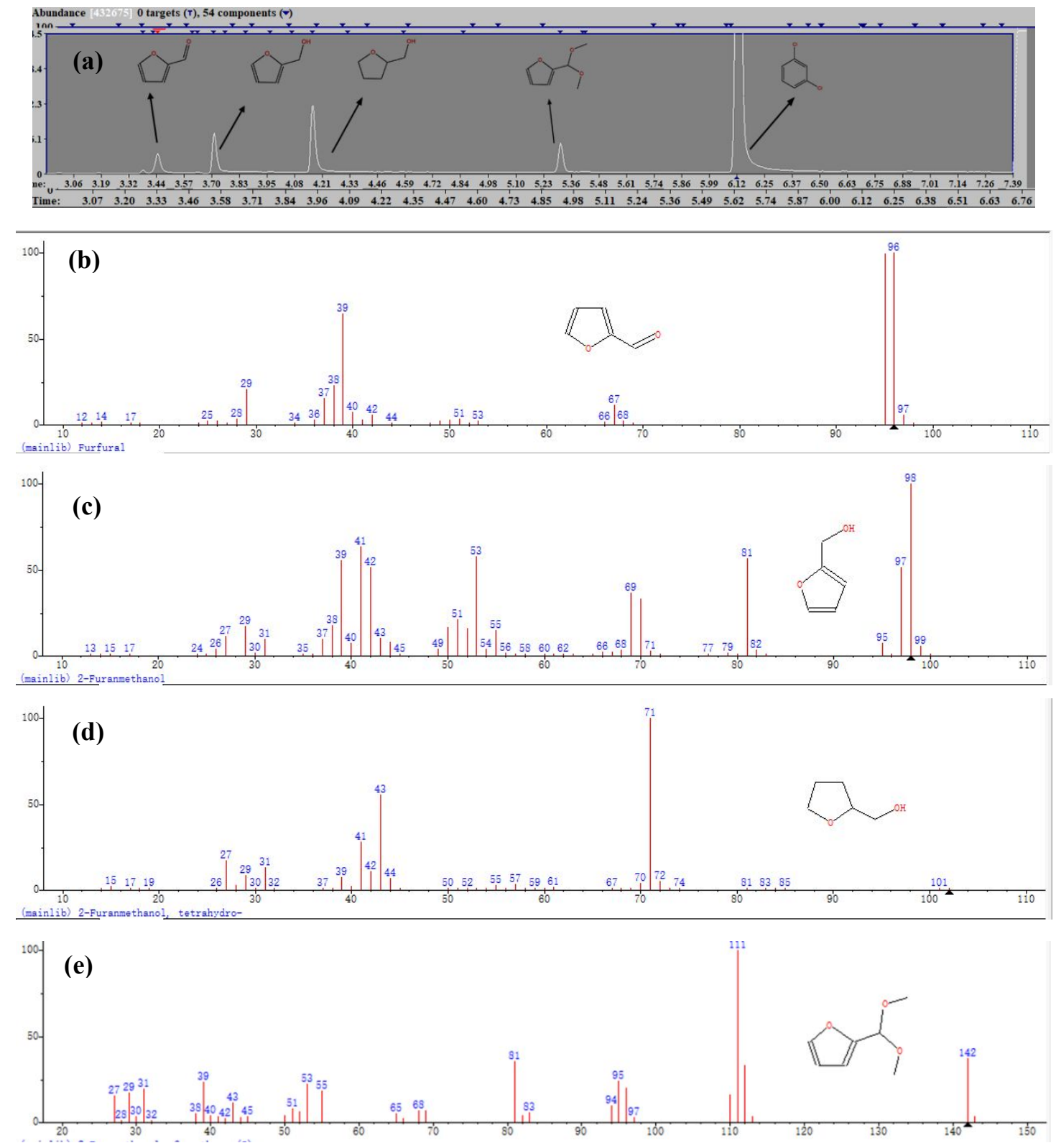

Figure S4. GC-MS analysis for products of furfual hydrogenation in methanol with Ni-MFC700 catalyst: (a) GC spectrum of the reaction mixtures; (b) MS analysis for furfural; (c) MS analysis for FOL; (d) MS analysis forTHFOL; (e) MS analysis fo racetal. 
Table S1. The Ni content in the Ni-MFC-500 and Ni-MFC-700 catalysts

\begin{tabular}{llll}
\hline Entry & Catalyst & Calculation $(\mathrm{mol} / \mathrm{g})$ & Found $(\mathrm{mol} / \mathrm{g})^{a}$ \\
\hline 1 & Ni-MFC-500 & $0.0046^{b}$ & 0.0043 \\
2 & Ni-MFC-500 (used) & & 0.0045 \\
3 & Ni-MFC-700 & $0.0049^{b}$ & 0.0044 \\
4 & Ni-MFC-700 (used) & & 0.0046
\end{tabular}

${ }^{a}$ The Ni content was determined by inductively coupled plasma spectroscopy (ICP).

${ }^{b}$ Ni content $(\mathrm{mol} / \mathrm{g})=\frac{\frac{m_{(N i-M F C)}}{\mathrm{M}_{(N i-M F C)}}}{\mathrm{m}_{(N i-M F C-A)}}(\mathrm{A}=500$ or 700$)$ 


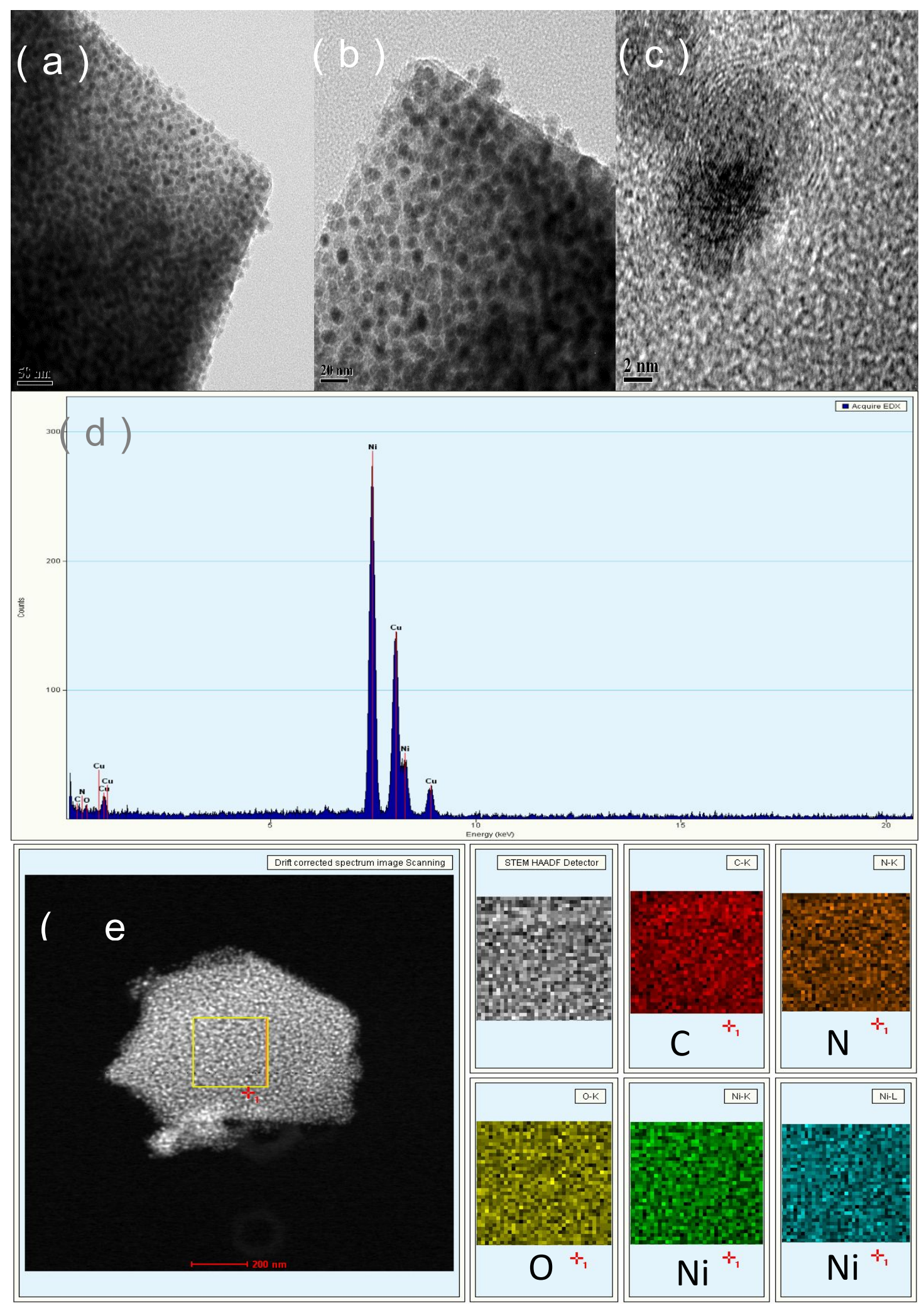

Figure S5. Element mapping and EDS from HRTEM images of Ni-MFC-500: (a), (b), (c)HRTEM images; (d) EDS; (e) Element mapping. 

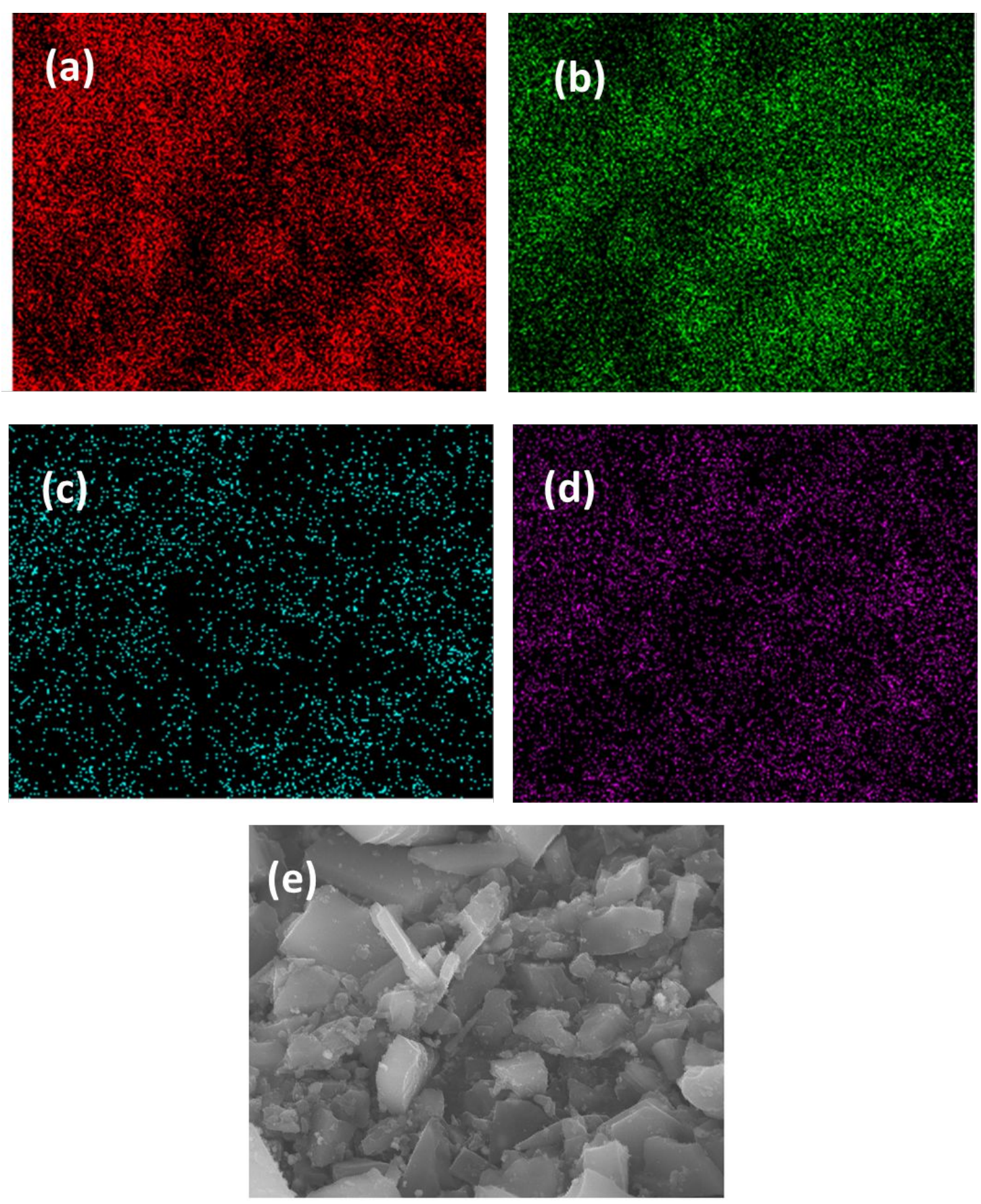

Figure S6. Element mapping from HRSEM images of Ni-MFC-500: (a) Ni; (b) C; (c) N; (d) $\mathrm{O}$; (e) SEM image. 

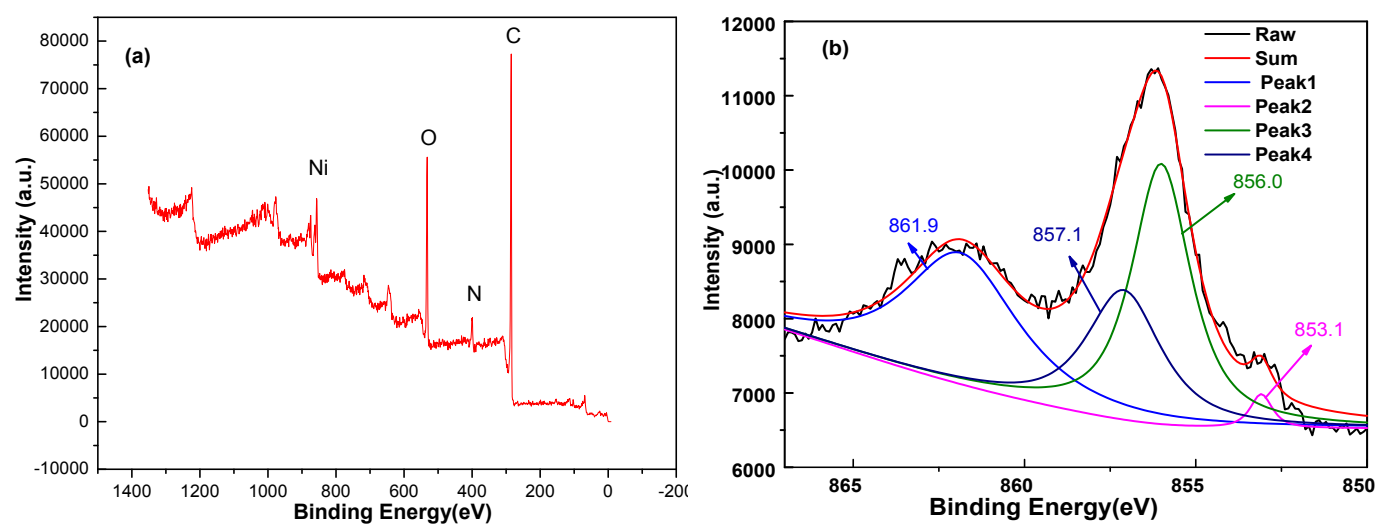

Figure S7. XPS analysis for the Ni-MFC-500: (a) survey scan; (b) Ni2p3/2
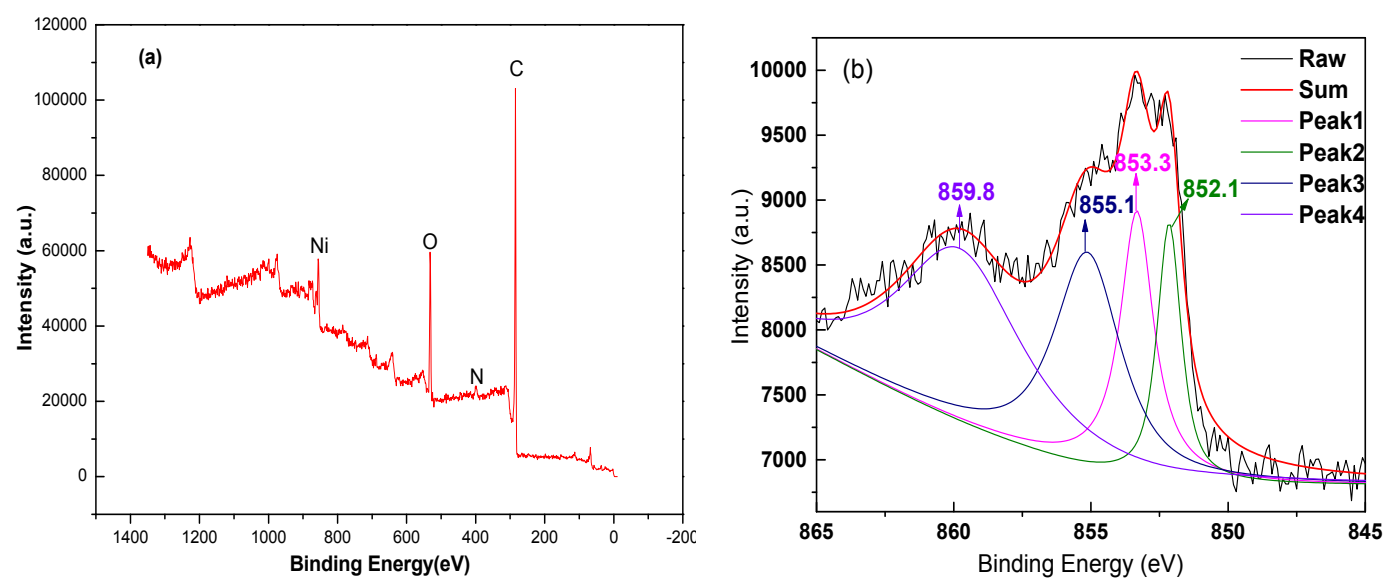

Figure S8. XPS analysis for Ni-MFC-700: (a) survey scan; (b) Ni2p3/2.

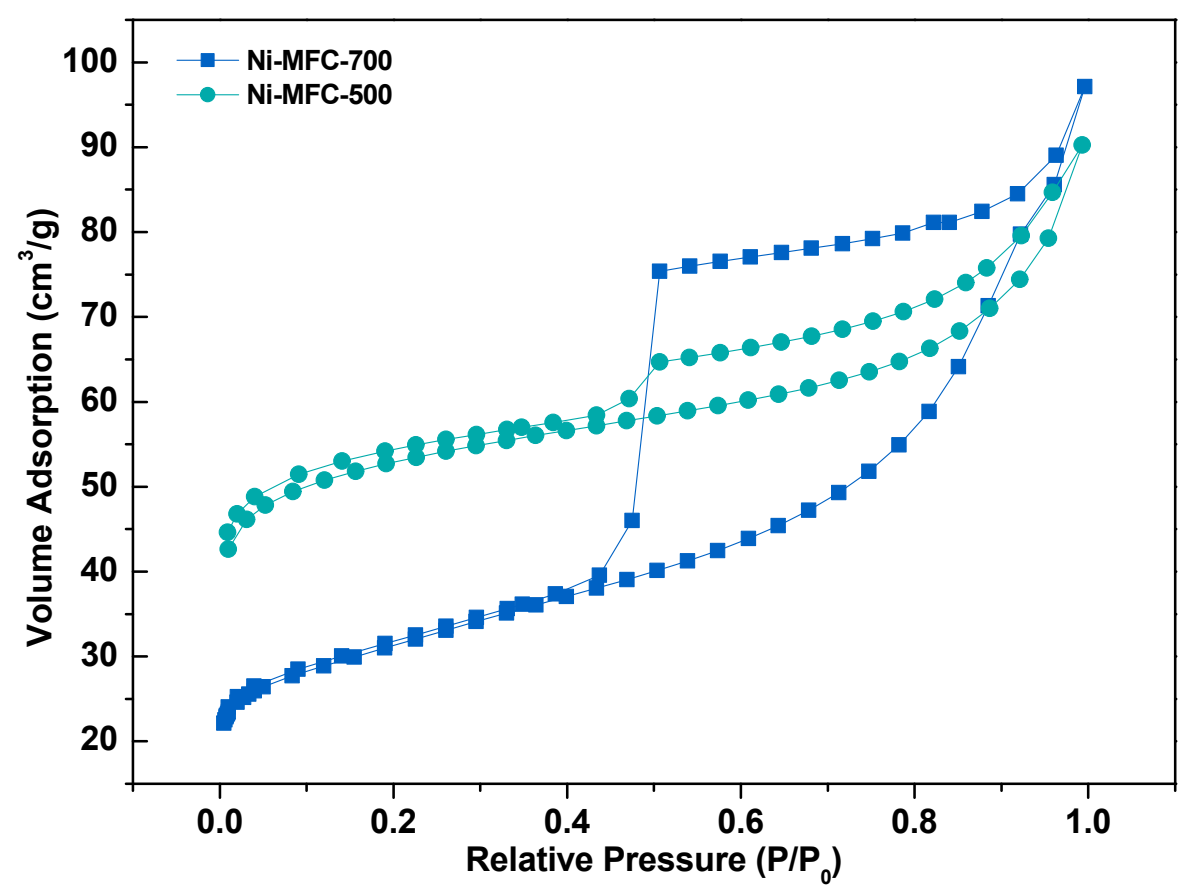

Figure S9. Nitrogen adsorption-desorption isotherm of the catalysts 
Table S2. Textural parameters for the derived Ni-MFC catalysts

\begin{tabular}{cccc}
\hline Catalysts & BET $\left(\mathrm{m}^{2} \mathrm{~g}^{-1}\right)$ & Pore size $(\AA)$ & Pore volume $\left(\mathrm{cm}^{3} \cdot \mathrm{g}^{-1}\right)$ \\
\hline Ni-MFC-500 & 119.4 & 46.1 & 0.14 \\
Ni-MFC-700 & 103.6 & 56.5 & 0.15 \\
\hline
\end{tabular}

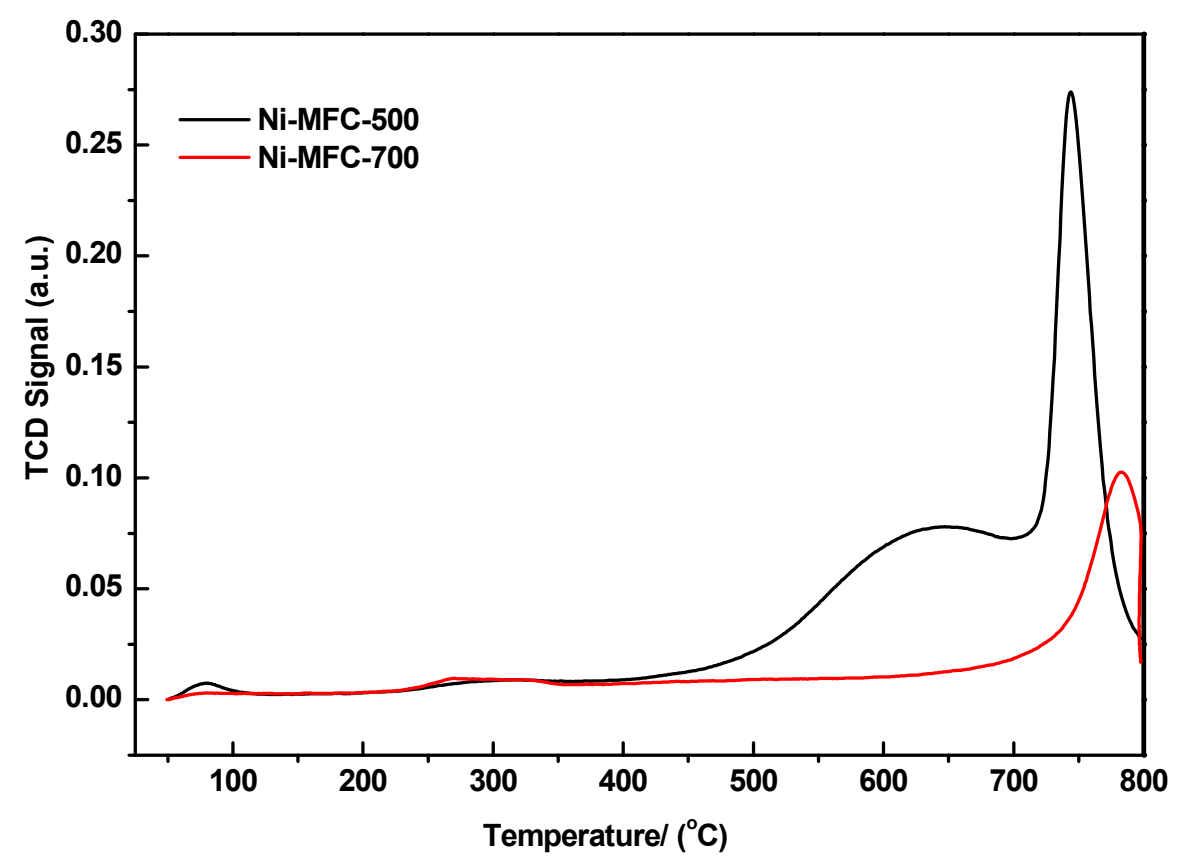

Figure S10. $\mathrm{CO}_{2}-\mathrm{TPD}$ profiles of the catalysts

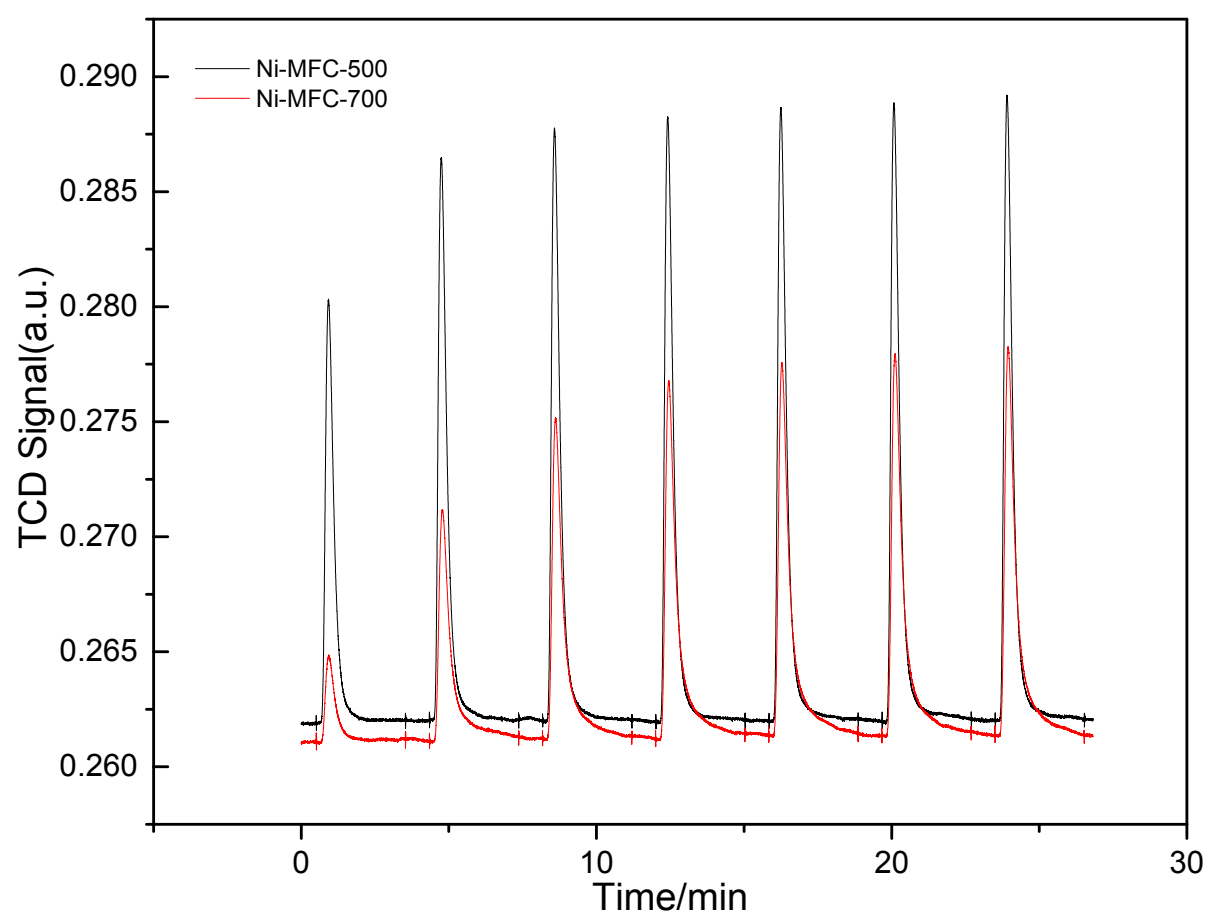


Figure. S11. $\mathrm{H}_{2}$-pulse chemisorption profiles of the catalysts

Table S3. $\mathrm{H}_{2}$-pulse chemisorption parameters for the derived Ni-MFC catalysts

\begin{tabular}{ccccc}
\hline Catalysts & Metal dispersion $(\%)$ & $\begin{array}{c}\text { Metallic surface area } \\
\left(\mathrm{m}^{2} / \mathrm{g} \text { sample }\right)\end{array}$ & $\begin{array}{c}\text { Metallic surface area } \\
\left(\mathrm{m}^{2} / \mathrm{g} \text { metal }\right)\end{array}$ & $\begin{array}{c}\text { particle diameter } \\
(\mathrm{nm})\end{array}$ \\
\hline Ni-MFC-500 & 0.2989 & 0.4979 & 1.9896 & 338.77 \\
Ni-MFC-700 & 0.5090 & 1.0165 & 3.3885 & 198.9 \\
\hline
\end{tabular}

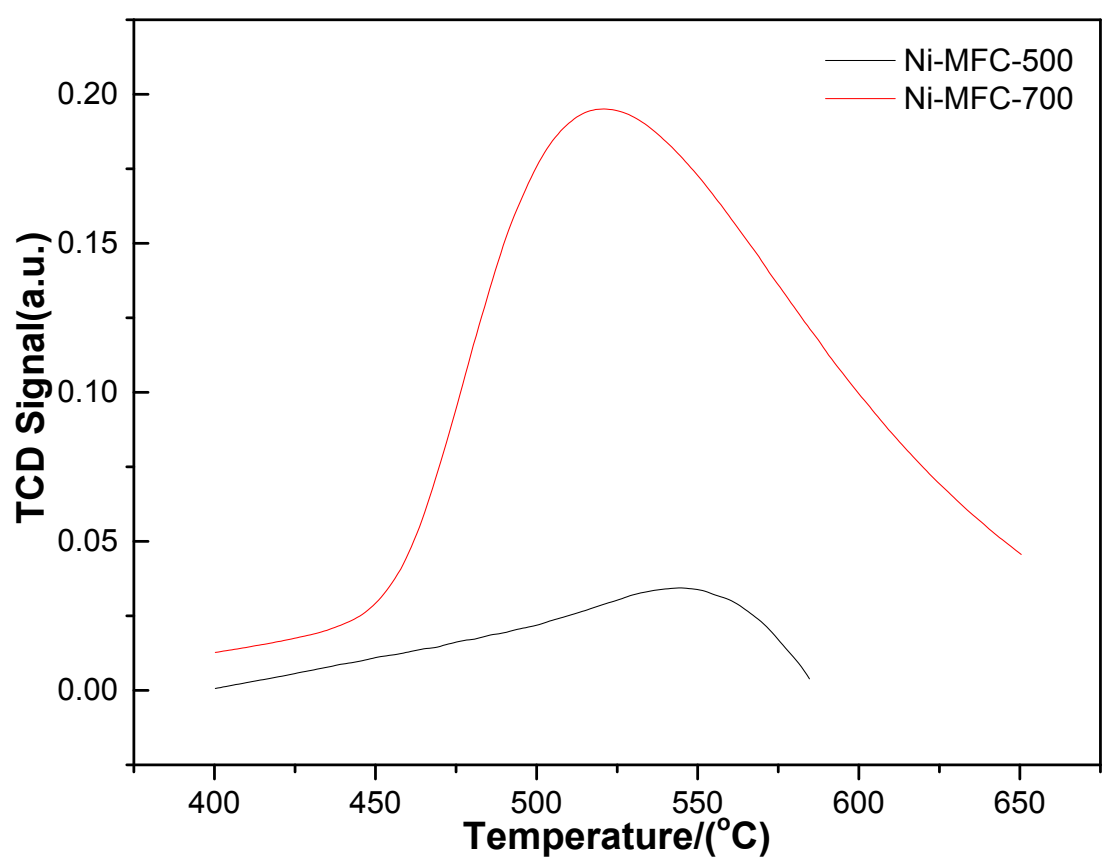

Figure S12. $\mathrm{H}_{2}$-TPR profiles of the catalysts

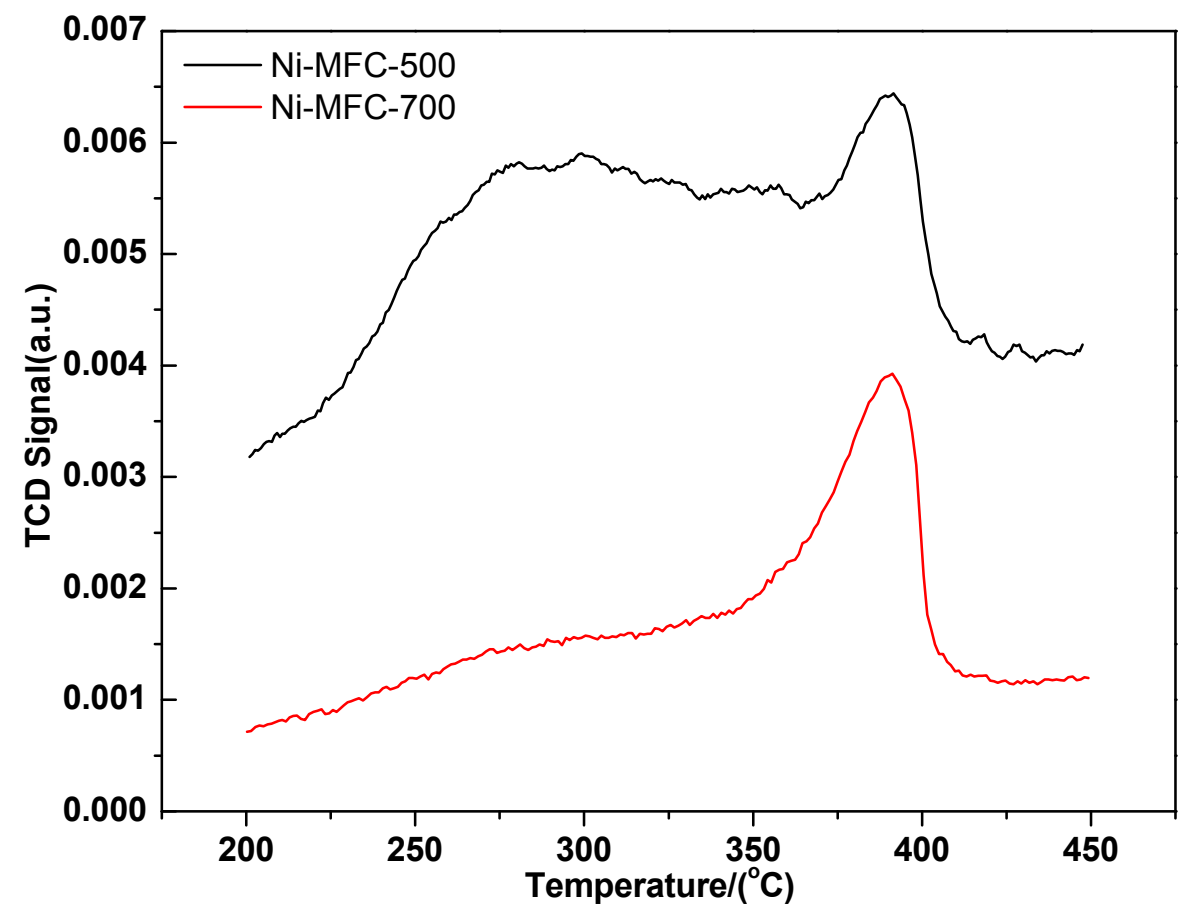

Figure S13. $\mathbf{N H}_{3}-\mathrm{TPD}$ profiles of the catalysts 